\title{
Peabody Picture Vocabulary Test-III: Normative data for Spanish-speaking pediatric population
}

L. Olabarrieta-Landa ${ }^{a}$, D. Rivera ${ }^{b}$, J.A. Ibáñez-Alfonso ${ }^{c}$, N. Albaladejo-Blázquez ${ }^{\text {d }}$,

P. Martín-Lobo ${ }^{\text {e }}$ I.D. Delgado-Mejía ${ }^{\mathrm{f}}$, L. Lara ${ }^{\mathrm{g}}$, B.V. Rabago Barajas ${ }^{\mathrm{h}}$, A.M. Rodriguez Salgado ${ }^{\mathrm{i}}$, L.A. Paredes Quispe ${ }^{j}$, I. Romero-Garcíak ${ }^{\mathrm{k}}$, J. Velázquez-Cardoso ${ }^{1}$, C. García de la Cadena ${ }^{\mathrm{m}}$,

I. Fernandez-Agis ${ }^{\mathrm{g}, \mathrm{n}}$, A. Padilla-López ${ }^{\mathrm{o}}$, G.P. Hernández Agurcia ${ }^{\mathrm{p}}$, A. Marín-Morales ${ }^{\mathrm{q}}$,

A. Corral San Josér and J.C. Arango-Lasprilla ${ }^{\mathrm{b}, \mathrm{s}, *}$

${ }^{a}$ Faculty of Psychology and Education, University of Deusto, Bilbao, Spain

${ }^{\mathrm{b}}$ BioCruces Health Research Institute, Cruces University Hospital, Barakaldo, Spain

${ }^{\mathrm{c}}$ Department of Psychology, Universidad Loyola Andalucía, Sevilla, Spain

${ }^{\mathrm{d}}$ Department of Health Psychology, University of Alicante, Alicante, Spain

${ }^{\mathrm{e}}$ Universidad Internacional de la Rioja (UNIR), Logroño, Spain

${ }^{\mathrm{f}}$ Universidad Autónoma de Asunción (UAA), Asunción, Paraguay

${ }^{\mathrm{g}}$ Universidad Autónoma de Chile, Talca, Chile

${ }^{\mathrm{h}}$ Departamento de Neurociencias, Universidad de Guadalajara (CUCS), Guadalajara, México

${ }^{\mathrm{i}}$ National Institute of Neurology and Neurosurgery INN, Havana, Cuba

${ }^{\mathrm{j}}$ Universidad Católica San Pablo, Arequipa, Perú

${ }^{\mathrm{k}}$ Universidad Interamericana de Puerto Rico, Recinto de San Germán, Puerto Rico

${ }^{1}$ Instituto Nacional de Neurología y Neurocirugía, MVS, Ciudad de México, México

${ }^{\mathrm{m}}$ Departamento de Psicología, Universidad del Valle de Guatemala, Guatemala City, Guatemala

${ }^{\mathrm{n}}$ Research Center CERNEP, Almeria University, Almería, Spain

${ }^{\mathrm{o}}$ Laboratorio de Psicofisiología, Facultad de Ciencias Humanas, Universidad Autónoma de Baja California, Mexicali, México

${ }^{\mathrm{p}}$ Escuela de Ciencias Psicológicas, Universidad Nacional Autónoma de Honduras, Tegucigalpa, Honduras

${ }^{\mathrm{q}}$ CIMCYC-The Mind, Brain and Behaviour Research Centre, Universidad de Granada, Granada, Spain

${ }^{\mathrm{r}}$ Hospital de Especialidades Eugenio Espejo, Servicio de Psicología Clínica, Quito, Ecuador

${ }^{\mathrm{s}}$ IKERBASQUE, Basque Foundation for Science, Bilbao, Spain

\begin{abstract}
.
OBJECTIVE: To generate normative data for the Peabody Picture Vocabulary Test-III (PPVT-III) in Spanish-speaking pediatric populations.

METHOD: The sample consisted of 4,373 healthy children from nine countries in Latin America (Chile, Cuba, Ecuador, Honduras, Guatemala, Mexico, Paraguay, Peru, and Puerto Rico) and Spain. Each participant was administered the PPVT-III as part of a larger neuropsychological battery. PPVT-III scores were normed using multiple linear regressions and standard deviations of residual values. Age, age ${ }^{2}$, sex, and mean level of parental education (MLPE) were included as predictors in the analyses.
\end{abstract}

*Address for correspondence: Juan Carlos Arango Lasprilla, Ph.D., BioCruces Health Research Institute, Cruces University Hospital, IKERBASQUE Basque Foundation for Science,
Plaza de Cruces s/n. 48903, Barakaldo, Bizkaia, Spain. Tel.: +34 946006000/Ext. 7963; E-mail: jcalasprilla@ gmail.com. 
RESULTS: The final multiple linear regression models showed main effects for age in all countries, such that scores increased linearly as a function of age. In addition, age ${ }^{2}$ had a significant effect in all countries, except Guatemala and Paraguay. Models showed that children whose parent(s) had a MLPE $>12$ years obtained higher scores compared to children whose parent(s) had a MLPE $\leq 12$ years in all countries, except for Cuba, Peru, and Puerto Rico. Sex affected scores for Chile, Ecuador, Guatemala, Mexico, and Spain.

CONCLUSIONS: This is the largest Spanish-speaking pediatric normative study in the world, and it will allow neuropsychologists from these countries to have a more accurate interpretation of the PPVT-III when used in pediatric populations.

Keywords: Peabody Picture Vocabulary Test-III, neuropsychology, Spanish-speaking populations, pediatric population

\section{Introduction}

Vocabulary is generally defined as the knowledge a person has regarding words and their meaning (Butler et al., 2010). Two types of vocabulary are identified: expressive vocabulary, which alludes to the words that a person can produce, and receptive vocabulary, which refers to the words that are acquired visually or aurally; that is, words that can be learned by hearing someone or by reading (Burger \& Chong, 2011).

Vocabulary development in children is fundamental for adequate school progress. Studies have shown that deficiencies in this aspect interfere with academic success resulting in reading comprehension difficulties (Pearson, Hiebert, \& Kamil, 2007; Stahl \& Fairbanks, 1986), and subsequent problems in the acquisition of new vocabulary. Studies also indicate that the vocabulary level attained by children is related to their overall linguistic and cognitive abilities (Feldman et al., 2005; Fernald, Perfors, \& Marchman, 2006; Marchman \& Fernald, 2008).

One of the most frequently utilized instruments in the measurement of vocabulary is the Peabody Picture Vocabulary Test-III (PPVT-III) (Pankratz, Morrison, \& Plante, 2004; Stockman, 2000). The test was developed to measure receptive vocabulary and to quickly determine verbal aptitude in a wide range of ages (2 years and a half to 90 years old; Dunn, Dunn, \& Arribas, 2010). The test involves presenting four images while the examiner says a word. The examinee must then indicate which image best represents the word said by the examiner (Dunn et al., 2010). The test advantages include quick administration time (between 10-15 minutes) and little oral communication from the examiner or the examinee, who can simply point to the answers. Accordingly, this test is particularly valuable for use with persons who are illiterate or those with aphasia, autism or cerebral palsy (Dunn et al., 2010).

The first edition was published in the United States of America (USA; Dunn, 1959) and was normed on Caucasian children. Later, in 1981, the PPVT revised
(PPVT-R) was developed, which sought to reduce gender, religion or race bias. At that time, the norming sample included children as well as adults in the USA ( 2 years and a half to 40 years of age), and two parallel forms were created (Forms L and M). For the third edition, in 1997, a concerted effort was made to include minority populations in the USA, such as Asians, African Americans, Hispanics and Native Americans. At this time, the age range was extended to 90 years of age. The USA edition has two parallel forms (Forms A and B), but the version from Spain only has one. According to the authors of the manual, this decision was prompted by their understanding that in the Hispanic context, the psychologist rarely needs two parallel versions to evaluate one aptitude (Dunn et al., 2010). For the Spanish norming, a total of 2,550 persons representing 19 provinces in Spain were included (Dunn et al., 2010). Lastly, the most recent version was published in 2007, the PPVT-IV. However, currently there is no version of that edition for Spain or any Latin American country. For that reason, the PPVT-III was used in the present study.

The PPVT-III was developed with the aim of being a culturally valid instrument. For that reason, as was previously mentioned in this document, the norming samples were broader and included ethnic minority representatives. This resulted in a third edition, which is the least culturally biased when compared to other versions of the PPVT. Evidence of adequate performance of this test has been obtained in studies with ethnic minority participants. For example, Washington and Craig (1999) found that the PPVT-III was an appropriate instrument for use with African American children. Haitana, Pitama, \& Rucklidge (2010) found the same with a sample of Maori children. Even so, there are researchers who argue that the inclusion of minority groups in the standardization sample does not free an instrument from cultural biases (Haitana et al., 2010). For example, a vocabulary test is based on the knowledge of word meaning, which can change depending on cultural experience (Stockman, 2000). This implies that word meaning can vary 
between people of different linguistic communities due to cultural nuances.

One must remember that the PPVT was initially created for use with English-speaking persons in the USA. Although it was translated into Spanish, and a Hispanic American version has been available since 1986 (Dunn, Lugo, Padilla, \& Dunn, 1986), the standardization of the PPVT-III was carried out only in Spain. For that reason, the use of the Spaniard norms in Latin American countries may not be adequate, even with the commonality of the Spanish language. Not only is their cultural background different, so is the frequency with which a specific word is used in each country. For example, the word "calcetín" [sock] is known by most Spanish-speakers, but it is not a frequently used word in Colombia, where it is commonly referred to as "media". Today, many professionals in Latin American countries utilize the PPVT-III version from Spain. However, despite its frequent use, norms for the PPVT-III are not available for Latin American countries. This makes it necessary to provide normative data for this population.

Furthermore, even though normative data is available for the population of Spain, it dates to the year 2003. Language changes overtime, and thus, the degree of difficulty of the PPVT-III stimuli may have transformed due to the frequency in the use of words by the current population. Words can change their meaning or can be substituted for others of increased present-day use. For example, several years ago the word "jolgorio" [revelry] was commonly utilized, but currently it is seldom used, and "fiesta ruidosa" [noisy party] is more commonplace. Thus, updated norms are also required for the population of Spain.

In view of the previously stated information, obtaining updated and adequate norms for each population is necessary. For that reason, the objective of the present study was to develop normative data for children and adolescents of nine countries in Latin America (Chile, Cuba, Ecuador, Guatemala, Honduras, Mexico, Paraguay, Peru, and Puerto Rico) and Spain.

\section{Method}

\subsection{Participants}

The sample consisted of 4,373 healthy children recruited from Chile, Cuba, Ecuador, Guatemala, Honduras, Mexico, Paraguay, Peru, Puerto Rico, and Spain. Participants were selected according to the fol- lowing criteria: a) between 6 and 17 years of age, b) born and currently lived in a country where the study was conducted, c) Spanish as primary language, d) an IQ $\geq 80$ on the Test of Non-Verbal Intelligence (TONI-2, Brown, Sherbenou, \& Johnsen, 2009), and e) scored $<19$ on the Children's Depression Inventory (CDI, Kovacs, 1992).

Children with history of neurologic or psychiatric disorders, as reported by the participant's parent(s), were excluded due to its effects on cognitive performance. Participants in the study were from public and private schools, and signed an informed consent. Socio-demographic and participant characteristics for each of the countries' samples have been reported elsewhere (Rivera \& Arango-Lasprilla, 2017). Ethics Committee approval was obtained for the study in each country.

\subsection{Instrument administration}

The PPVT-III has the dual purpose of measuring receptive vocabulary and serving as a screening method for verbal aptitude for children two and a half years and older (Bell, Lassiter, Matthews, \& Hutchinso, 2001). The test consists of 4 training sheets and 192 test sheets arranged in order of increasing difficulty (Dunn \& Dunn, 1997). Each test sheet includes 4 black and white images, of which the participant has to select the image that best corresponds to the word prompt (Dunn et al., 2010). To get the total score subtract the number of errors from the ceiling item.

\subsection{Statistical analyses}

Detailed statistical analyses used to generate the normative data for the PPVT-III Total score are described in Rivera \& Arango-Lasprilla (2017). In summary, the scores were standardized using multiple linear regressions analyses by means of a four-step procedure. 1) First, the PPVT-III Total scores were computed by means of the final multiple regression models. The full regression models included as predictors: age, age $^{2}$, sex, and mean level of parental education (MLPE). Age was centered (=calendar age - mean age in the sample by country) before computing the quadratic age term to avoid multicollinearity (Aiken \& West, 1991). Sex was coded as male $=1$ and female $=0$. The MLPE variable was coded as 1 if the participant's parent(s) had $>12$ years of education or 0 if participant's parent(s) had $\leq 12$ years of education. If predicted variables were 
not statistically significant in the multivariate model with an alpha of 0.05 , the non-significant variables were removed and the model reanalyzed. A final regression model was conducted: $\hat{y}_{i}=\mathrm{B}_{0}+\mathrm{B}_{1}$. $\left(\text { Age }-\bar{x}_{\text {Age by country }}\right)_{i}+\mathrm{B}_{2} \cdot\left(\text { Age }-\bar{x}_{\text {Age by country }}\right)_{i}^{2}$ $+\mathrm{B}_{3} \cdot \operatorname{Sex}_{i}+\mathrm{B}_{4} \cdot M L P E_{i}$. 2) Residual scores were calculated based on the final model $\left(e_{i}=y_{i}-\hat{y}_{i}\right)$. 3) Residuals were standardized using the residual Standard Deviation $\left(S D_{e}\right)$ value provided by the regression model: $z_{i}=e_{i} / S D_{e}$. 4) Standardized residuals were converted to percentile values using the standard normal cumulative distribution function. This four-step process was applied to PPVT-III Total score separately for each country.

For all multiple linear regression models, the following assumptions were evaluated: a) multicollinearity by the values of the Variance Inflation Factor (VIF), which must not exceed 10, and the collinearity tolerance values, which must not exceed the value of 1 (Kutner, Nachtsheim, Neter, \& Li, 2005), and b) the existence of influential values by calculating the Cook's distance. The maximum Cook's distance value was related to a $F(p, n-p)$ distribution. Influential values are considered when percentile value is equal or higher than 50 (Cook, 1977; Kutner et al., 2005). All analyzes were performed using SPSS version 23 (IBM Corp., Armonk, NY).

\section{Results}

The final multivariate linear regression models for the ten country-specific PPVT-III Total scores were significant (see Table 1). In all countries, the PPVTIII Total scores increased linearly as a function of age. The PPVT-III Total scores for Chile, Cuba, Ecuador, Honduras, Mexico, Peru, Puerto Rico, and Spain were also affected by a quadratic age effect. Children from Chile, Ecuador, Guatemala, Honduras, Mexico, Paraguay, and Spain who had parent(s) with a MLPE $>12$ years obtained higher PPVT-III Total score than children who had PPVT-III Total score with a MLPE $\leq 12$ years. The child's sex affected the PPVT-III Total scores for Chile, Ecuador, Guatemala, Mexico, and Spain, so that boys achieved higher score than girls. The amount of variance these predictors explained in PPVT-III Total scores ranged from $46.0 \%$ (in Guatemala) to $72.1 \%$ (in Cuba). The assumptions of multiple linear regression analysis were met for all final models. There was not multicollinearity (the VIF values were below 10; VIF
Table 1

Final multiple linear regression models for PPVT-III

\begin{tabular}{|c|c|c|c|c|c|c|}
\hline & B & $\begin{array}{l}\text { Std. } \\
\text { Error }\end{array}$ & $t$ & Sig. & $R^{2}$ & $\begin{array}{c}S D e \\
\text { (residual) }\end{array}$ \\
\hline \multicolumn{7}{|l|}{ Chile } \\
\hline Constant & 114.704 & 1.981 & 57.902 & $<0.001$ & 0.551 & 20.356 \\
\hline Age & 6.367 & 0.306 & 20.780 & $<0.001$ & & \\
\hline $\mathrm{Age}^{2}$ & -0.262 & 0.100 & -2.631 & 0.009 & & \\
\hline MLPE & 6.285 & 2.236 & 2.811 & 0.005 & & \\
\hline Sex & 9.427 & 2.118 & 4.451 & $<0.001$ & & \\
\hline \multicolumn{7}{|l|}{ Cuba } \\
\hline Constant & 133.599 & 1.006 & 132.797 & $<0.001$ & 0.721 & 12.962 \\
\hline Age & 5.856 & 0.193 & 30.365 & $<0.001$ & & \\
\hline $\mathrm{Age}^{2}$ & -0.456 & 0.063 & -7.206 & $<0.001$ & & \\
\hline \multicolumn{7}{|l|}{ Ecuador } \\
\hline Constant & 116.563 & 1.948 & 59.844 & $<0.001$ & 0.655 & 14.145 \\
\hline Age & 5.508 & 0.241 & 22.881 & $<0.001$ & & \\
\hline $\mathrm{Age}^{2}$ & -0.483 & 0.080 & -6.034 & $<0.001$ & & \\
\hline MLPE & 6.266 & 1.889 & 3.317 & 0.001 & & \\
\hline Sex & 4.098 & 1.681 & 2.438 & 0.015 & & \\
\hline \multicolumn{7}{|l|}{ Guatemala } \\
\hline Constant & 103.874 & 2.066 & 50.279 & $<0.001$ & 0.460 & 18.012 \\
\hline Age & 6.276 & 0.528 & 11.882 & $<0.001$ & & \\
\hline MLPE & 9.077 & 2.964 & 3.062 & 0.003 & & \\
\hline Sex & 6.222 & 2.601 & 2.392 & 0.018 & & \\
\hline \multicolumn{7}{|l|}{ Honduras } \\
\hline Constant & 118.294 & 1.554 & 76.146 & $<0.001$ & 0.625 & 15.403 \\
\hline Age & 6.171 & 0.284 & 21.765 & $<0.001$ & & \\
\hline $\mathrm{Age}^{2}$ & -0.410 & 0.091 & -4.487 & $<0.001$ & & \\
\hline MLPE & 4.014 & 1.830 & 2.194 & 0.029 & & \\
\hline \multicolumn{7}{|l|}{ Mexico } \\
\hline Constant & 113.878 & 1.146 & 99.366 & $<0.001$ & 0.667 & 16.194 \\
\hline Age & 6.218 & 0.153 & 40.519 & $<0.001$ & & \\
\hline $\mathrm{Age}^{2}$ & -0.521 & 0.051 & -10.272 & $<0.001$ & & \\
\hline MLPE & 10.849 & 1.079 & 10.059 & $<0.001$ & & \\
\hline Sex & 3.755 & 1.071 & 3.506 & $<0.001$ & & \\
\hline \multicolumn{7}{|l|}{ Paraguay } \\
\hline Constant & 114.672 & 2.300 & 49.855 & $<0.001$ & 0.465 & 23.707 \\
\hline Age & 6.130 & 0.396 & 15.481 & $<0.001$ & & \\
\hline MLPE & 10.000 & 2.876 & 3.476 & 0.001 & & \\
\hline \multicolumn{7}{|l|}{ Peru } \\
\hline Constant & 127.990 & 1.396 & 91.651 & $<0.001$ & 0.665 & 17.105 \\
\hline Age & 6.843 & 0.286 & 23.898 & $<0.001$ & & \\
\hline $\mathrm{Age}^{2}$ & -0.405 & 0.094 & -4.310 & $<0.001$ & & \\
\hline \multicolumn{7}{|l|}{ Puerto Rico } \\
\hline Constant & 120.607 & 1.915 & 62.977 & $<0.001$ & 0.601 & 17.169 \\
\hline Age & 5.686 & 0.367 & 15.491 & $<0.001$ & & \\
\hline $\mathrm{Age}^{2}$ & -0.266 & 0.120 & -2.209 & 0.028 & & \\
\hline \multicolumn{7}{|l|}{ Spain } \\
\hline Constant & 129.260 & 1.114 & 115.992 & $<0.001$ & 0.691 & 15.411 \\
\hline Age & 6.819 & 0.149 & 45.819 & $<0.001$ & & \\
\hline $\mathrm{Age}^{2}$ & -0.452 & 0.048 & -9.394 & $<0.001$ & & \\
\hline MLPE & 6.390 & 1.033 & 6.184 & $<0.001$ & & \\
\hline Sex & 3.892 & 0.992 & 3.924 & $<0.001$ & & \\
\hline
\end{tabular}

Note. MLPE: Mean level of parental education.

$\leq 1.131$; collinearity tolerance values did not exceed the value of 1 ) or influential cases (the maximum Cook's distance value was 0.184 in a $F_{(3,212)}$ distribution which correspond to percentile 9 ). 


\subsection{Normative procedure}

Norms (e.g., a percentile score) for the PPVT-III Total scores by country were established using the four-step procedure described in the statistical analysis section. An example will be provided to facilitate understanding of the procedure used to obtain the percentile associated with a score on this test. In order to identify the percentile score for an 8-year-old Mexican girl who scored 102 on the PPVT-III and whose parent(s) have a MLPE of 14 years. The steps to obtain the percentile for this score are: 1) Find Mexico in Table 1, which provides the final regression models by country for the PPVT-III Total score. Next, use the $\mathrm{B}$ weights to create an equation that will allow for obtaining the predicted total score for this child using the coding provided in the statistical analysis section. The corresponding B weights are multiplied by the centered age (=calendar age - mean age in the Mexican sample which is equal to 11.4 years), centered $\operatorname{age}^{2}$ (= calendar age - mean age in the Mexican sample which is equal to 11.4 years $)^{2}$, MLPE code based on the 12 years of education threshold, and sex which was coded as male $=1$ and female $=0$. See Rivera \& Arango-Lasprilla (2017) to find the mean age of each country's sample. The result is then added to the constant generated by the model in order to calculate the predicted value.

In the case of the 8-year-old Mexican girl, the predicted PPVT-III Total score would be calculated using the following equation: $\hat{y}_{i}=113.878+[6.218$. $\left.\left(\mathrm{Age}_{i}-11.4\right)\right]+\left[-0.521 \cdot\left(\mathrm{Age}_{i}-11.4\right)^{2}\right]+(3.755$ - Sex $)+(10.849 \cdot M L P E)$. The child's age is 8 and the child's sex is female, so the sex value is 0 . The MLPE (14 years) is split into either $\leq 12$ years (and assigned a 0 ) or more than 12 years (and assigned a 1 ) in the model. Since the parent(s) of the hypothetical child in the example have 14 years of education, the MLPE value is 1 . Thus, the predicted value equation is: $\hat{y}_{i}=113.878+[6.218 \cdot(8-11.4)]+[-0.521$. $\left.(8-11.4)^{2}\right]+(3.755 \cdot 0)+(10.849 \cdot 1)=113.878$ $+(-21.141)+(-6.022)+0+10.849=97.564$.

2) In order to calculate the residual value (indicated with an $e$ in the equation), subtract the actual PPVT-III Total score (she scored 102) from the predicted value we just calculated $\left(e_{i}=y_{i}-\hat{y}_{i}\right)$. In this case, it would be $e_{i}=102-97.564=4.436 .3$ ) Next, consult the $S D_{e}$ column in Table 1 to obtain the country-specific $S D_{e}$ (residual) value. For Mexico, it is 16.194. Using this value, we can transform the residual value to a standardized $z$ score using the equation $z_{i}=e_{i} / S D_{e}$. In this case, the values are
$4.436 / 16.194=0.273$. This is the standardized $z$ score for an 8-year-old Mexican girl who scored 102 on the PPVT-III Total score who has parent(s) with a MLPE of 14 years. 4) The last step is to use the tables available in most statistical reference books (e.g., Strauss, Sherman, \& Spreen, 2006) to convert $\mathrm{z}$ scores to percentiles. In this example, the $z$ score (probability) of 0.273 corresponds to the $61^{\text {st }}$ percentile.

\subsection{User-friendly normative data}

The four-step normative procedures explained above offer the clinician the ability to determine an exact percentile for a child who has a specific score on the PPVT-III Total score. However, this method can be prone to human error due to the number of required computations by hand. To enhance user-friendliness, the authors have completed these steps for a range of raw scores based on age, sex, and MLPE and created tables for clinicians to more easily obtain a percentile range/estimate associated with a given raw score on this test. These tables are available by country in the Appendixes. In order to obtain an approximate percentile for the above example (converting a raw score of 102 on the PPVT-III Total score for a Mexican girl who is 8 years old and whose parent(s) have 14 years of education) using the simplified normative tables provided in the Appendixes, the following steps must be followed. (1) First, identify the appropriate table ensuring the appropriate country. In this case, the table for the PPVT-III Total score for female of Mexico can be found in Table A10. (2) Next, the table is divided based on MLPE ( $\leq 12$ vs. more than 12 years of education). Since the parent(s) had 14 years of education, we will use the upper section of the table for $>12$ years of MLPE. (3) Find the appropriate age of the child, in this case, 8 years old. (4) Next, look in the 8 years' age column to find the approximate location of the raw score obtained on the test. Within the 8 years' column, the score of 102 obtained by this Mexican girl corresponds to an approximate percentile of 60 .

The percentile obtained using this user-friendly table sometimes could be slightly different than the hand-calculated, more accurate method $\left(61^{\text {st }}\right.$ vs. $\left.60^{\text {th }}\right)$ because the user-friendly table is based on a limited number of percentile values. Individual percentiles cannot be presented in these tables due to space limitations. If the exact score is not listed in the column, you must estimate the percentile value from the list of raw scores available. 


\section{Discussion}

The purpose of the present study was to obtain normative data for the PPVT-III for children and adolescents from nine Latin American countries (Chile, Cuba, Ecuador, Guatemala, Honduras, Mexico, Paraguay, Peru, and Puerto Rico) and Spain. The final regression models for the PPVT-III accounted for $46.0 \%$ and $72.1 \%$ of the variance.

There are very few normative data studies published for the PPVT-III, thus comparison with the existing literature is complicated. The age variable was significantly related to the Total scores of the PPVT-III, such that scores increased linearly as children become older. This gradual increase in performance as age advances is in line with the results of a normative study carried out in Spain (Dunn et al., 2010). The authors reported a gradual increase in the total score of the PPVT-III, with an increase being especially noticeable between the ages of 12 and 16, until stabilization begins at the age of 17, especially between 19 and 20 years of age (Dunn et al., 2010). Results of the present study showed a curvilinear relationship of age and relative scores on the PPVT-III (reference score was a 6-year-old boy with high-educated parents). This relationship indicates that relative scores increase as age advances, with the most prominent increase in younger children than older ones. For example, the difference in relative scores for a 6-year-old boy with high-educated parents (reference value) compared to a 7-year-old with the same characteristics ranges from $6.8 \%$ to $14 \%$ percent depending on country of origin, while the difference in relative scores for a 14-year-old with those same characteristics compared to a 15 -year-old is only $1.8 \%$ to $4.5 \%$.

This gradual increase in PPVT-III scores coincides with studies that have attempted to determine the development of vocabulary during childhood, adolescence, and adulthood. For example, Biemiller and Slonim (2001) estimated that English-speaking children in the second grade knew an average of 5,200 words and attaining 8,400 words by the fifth grade. According to Guerra, Williamson, \& LucasMolina (2012), vocabulary continues to expand during middle childhood, reaching 40,000 words during adolescence (18 years). Sullivan \& Brown (2014) also reported a progressive increase in vocabulary in people aged 16 to 42 years. In addition, vocabulary is quite resistant to decline during normal aging, which can remain stable and even improve over time (Harada, Love, \& Triebel, 2013).
The MLPE was also associated with PPVT-III Total scores. Van der Elst, Hurks, Wassenberg, Meijs, \& Jolles (2011) were the first to use MLPE as a variable associated with verbal fluency tests in their normative data study. Van der Elst et al. (2011) reported that children whose parent(s) had a higher educational level did better on these tests as compared to children whose parent(s) had a lower educational level. Normative studies on the PPVT-III have not developed norms using this variable but a number of studies have looked at its influence on performance. For example, educational level of parent(s) of African-American children was related to the score obtained by children in the PPVT-III, such that children whose parent(s) had completed high school or college, scored higher than children whose parent(s) had not finished high school (Washington \& Craig, 1999).

The fact that parents' educational level influences the score obtained by children in the PPVT-III is not surprising since research has shown that vocabulary level obtained by children depends to a large extent on the environment in which they developed. For example, children from higher socioeconomic backgrounds had a higher level of vocabulary than those from lower socioeconomic backgrounds (Hoff, 2003). Similarly, children's scores on the vocabulary task of the British Ability Scales battery depended heavily on parental education (Becker, 2011). Thus, children whose parent(s) had a high educational level had a broader vocabulary than children whose parents had a lower educational level. In addition, this study showed that early schooling of children positively influenced the development of vocabulary, but only in those children whose parent(s) had a lower educational level. It seems that the way parent(s) interact with their children and the stimulation they offer (e.g. reading books) is helpful for language development as well as the socioeconomic level (Becker, 2011).

Finally, the variable gender was associated with performance in the PPVT-III, such as males achieves higher scores than females. Dunn et al. (2010) found that gender had a small influence on PPVTIII Total scores, thus only norms based on age were created.

\subsection{Limitations and future directions}

The study has some limitations. First, only children whose primary language was Spanish were recruited. Therefore, the results of this study cannot be general- 
ized to children who speak a region-specific language in addition to Spanish. This is noteworthy because many countries in Latin America and Spain are multilingual (Chamoreau, 2014; Garrido Medina, 2007). Future studies should develop norms in the languages spoken in these countries.

Second, the results of this study cannot be generalized to other Latin American countries such as Argentina, Bolivia, Panama or Venezuela. Future studies should obtain normative data for the PPVT-III in the Latin American countries not represented in the present study. This will offer a more comprehensive accounting of normative data in this region.

Third, the samples collected in Chile, Mexico, Paraguay, Puerto Rico, and Spain represent data from several areas of the countries, for the rest of the countries of the study only children from a specific area were recruited. It would have been ideal to recruit children from different areas of all the countries represented. Future studies should expand the data from this study with samples from different regions within the countries. Likewise, most of the children were recruited from urban areas, thus future studies should include more children from rural areas.

Fourth, the PPVT-III can be applied to children under the age of 6 and adults up to the age of 90; thus, future studies could obtain normative data for children between the ages 2 and a half and 5, and adults between the ages 18 and 90. Finally, normative data were generated using healthy children and adolescents. Future studies should include clinical samples (e.g., children and adolescents with brain damage, epilepsy, etc.) in order to obtain cutoff points and to calculate the sensitivity and specificity of the PPVT-III.

\subsection{Implications and conclusions}

The level of vocabulary acquisition is an important aspect to assess during neuropsychological evaluation, since vocabulary is closely related to reading comprehension and academic success. Professionals in Latin America and Spain often use the PPVTIII as a measure of vocabulary in both children and adults during their clinical work. Now, professionals from nine countries in Latin America and Spain have normative data available for the PPVT-III for children and adolescents. Availability of these norms will be valuable for professionals in these countries and enhance the evaluation and diagnosis for these groups.

\section{Conflict of interest}

\author{
None to report.
}

\section{Supplementary material}

The Appendix tables are available in the electronic version of this article: http://dx.doi.org/10.3233/ NRE-172239.

\section{References}

Aiken, L. S., \& West, S. G. (1991). Multiple regression: Testing and interpreting interactions. Newbury Park, CA: Sage.

Becker, B. (2011). Social disparities in children's vocabulary in early childhood. Does pre-school education help to close the gap? The British Journal of Sociology, 62(1), 69-88.

Bell, N. L., Lassiter, K. S., Matthews, T. D., \& Hutchinson, M. B. (2001). Comparison of the peabody picture vocabulary test-Third edition and Wechsler adult intelligence scale-Third edition with university students. Journal of Clinical Psychology, 57(3), 417-422.

Biemiller, A. \& Slonim, N. (2001) Estimating root word vocabulary growth in normative and advantaged populations: Evidence for a common sequence of vocabulary acquisition. Journal of Educational Psychology, 93(3), 498-520.

Brown, L., Sherbenou, R. J., \& Johnsen, S. K. (2009). Test de inteligencia no verbal TONI-2. Madrid: TEA ediciones.

Burger, A., \& Chong, I. (2011). Receptive vocabulary. In S. Goldstein \& J. A. Naglieri. Encyclopedia of Child Behavior and Development. Springer US.

Butler, S., Urrutia, K., Buenger, A., Gonzalez, N., Hunt, M., \& Eisenhart, C. (2010). A Research Synthesis: A Review of the Current Research on Vocabulary Instruction. National reading Technical Assistance Center, RMC Research Corporation.

Chamoreau, C. (2014). Diversidad lingüística en México. Amerindia - Langues du Mexique, 37(1), 3-20.

Cook, R. D. (1977). Detection of influential observation in linear regression. Technometrics, 19(1), 15-18. doi: 10.2307/ 1268249

Dunn, L. M. (1959). Peabody Picture Vocabulary Test. Minneapolis: American Guidance Service.

Dunn, L. M., \& Dunn, L. M. (1997). Examiner's manual for the Peabody Picture Vocabulary Test Third Edition. Circle Pines, Minn.: American Guidance Service.

Dunn, L. M., Dunn, L. M. \& Arribas, D. (2010). PPVT-III Peabody Test de vocabulario en imágenes. Manual. Madrid: TEA Ediciones.

Dunn, L. M., Lugo, D. E, Padilla, E. R., \& Dunn, L. M. (1986). Test de Vocabulario en Imágenes Peabody. American Guidance Service; Circle Pines, MN.

Feldman, H. M., Dale, P. S., Campbell, T. F., Colborn, D. K., Kurs-Lasky, M., Rockette, H. E., \& Paradise, J. L. (2005). Concurrent and predictive validity of parent reports of child language at ages 2 and 3 years. Child Development, 76(4), 856-868. 
Fernald, A., Perfors, A., \& Marchman, V. A. (2006). Picking up speed in understanding: Speech processing efficiency and vocabulary growth across the 2 nd year. Developmental Psychology. 42(1):98-116.

Garrido Medina, J. C. (2007). Multilingüismo y lengua externa e interna en la política lingüística en España. Anuario de estudios filológicos, 30, 131-149.

Guerra, N. G., Williamson, A. A., \& Lucas-Molina, B. (2012). Normal development: Infancy, childhood, and adolescence. In J. M. Rey (ed), IACAPAP e-Textbook of Child and Adolescent Mental Health (pp. 1-39). Geneva: International Association for Child and Adolescent Psychiatry and Allied Professions 2012.

Haitana, T., Pitama, S., \& Rucklidge, J. J. (2010). Cultural biases in the Peabody Picture Vocabulary Test-III: Testing Tamariki in a New Zealand Sample. New Zealand Journal of Psychology, 39(3), 24-34.

Harada, C. N., Love, M. C. N., \& Triebel, K. L. (2013). Normal cognitive aging. Clinics in Geriatric Medicine, 29(4), 737-752.

Hoff, E. (2003). The specificity of environmental influence: Socioeconomic status affects early vocabulary development via maternal speech. Child Development, 74(5), 1368-1378.

Kovacs, M. (1992). Children Depression Inventory CDI (Manual). Toronto: Multihealth systems.

Kutner, M. H., Nachtsheim, C. J., Neter, J., \& Li, W. (2005). Applied linear statistical models (5th ed.). New York: McGraw Hill.

Marchman, V. A., \& Fernald, A. (2008). Speed of word recognition and vocabulary knowledge in infancy predict cognitive and language outcomes in later childhood. Developmental Science, 11(3), F9-F16. http://doi.org/10.1111/j.14677687.2008.00671.x
Pankratz, M., Morrison, A., \& Plante, E. (2004). Difference in standard scores of adults on the Peabody Picture Vocabulary Test (Revised and Third Edition). Journal of Speech, Language, and Hearing Research, 47(3), 714-718.

Pearson, P. D., Hiebert, E. H., \& Kamil, M. L. (2007). Vocabulary assessment: What we know and what we need to learn. Reading Research Quarterly, 42(2), 282-296.

Rivera, D., \& Arango-Lasprilla, J. C. (2017). Methodology for the development of normative data for Spanish Speaking pediatric population. NeuroRehabilitation.

Stahl, S. A., \& Fairbanks, M. M. (1986). The effects of vocabulary instruction: A model-based meta-analysis. Review of Educational Research, 56(1), 72-110.

Stockman, I. J. (2000). The new Peabody Picture Vocabulary TestIII: An illusion of unbiased assessment? Language, Speech \& Hearing Services in Schools, 31(4), 340-353.

Strauss, E., Sherman, E. M., \& Spreen, O. (2006). A compendium of neuropsychological tests: Administration, norms, and commentary. American Chemical Society.

Sullivan, A. \& Brown, M. (2014). Vocabulary from adolescence to middle-age. Centre for Longitudinal Studies, University of London.

Van der Elst, W., Hurks, P., Wassenberg, R., Meijs, C., \& Jolles, J. (2011). Animal Verbal Fluency and Design Fluency in schoolaged children: Effects of age, sex, and mean level of parental education, and regression-based normative data. Journal of Clinical \& Experimental Neuropsychology, 33(9), 1005-1015. doi: 10.1080/13803395.2011.589509

Washington, J. A., \& Craig, H. K. (1999). Performances of atrisk, African American preschoolers on the peabody picture vocabulary test-III. Language, Speech, and Hearing Services in Schools, 30(1), 75-82. 